\title{
Ectopic Growth Hormone Secretion Syndrome
}

National Cancer Institute

\section{Source}

National Cancer Institute. Ectopic Growth Hormone Secretion Syndrome. NCI

Thesaurus. Code C8440.

A syndrome characterized by abnormal secretion of growth hormone in conjunction with neoplastic growth occurring anywhere in the body. 